\title{
Intraocular lenses in children: changes in axial length, corneal curvature, and refraction
}

\author{
D I Flitcroft, D Knight-Nanan, R Bowell, B Lanigan, M O'Keefe
}

\begin{abstract}
Aim-To assess changes in axial length, corneal curvature, and refraction in paediatric pseudophakia.

Methods-35 eyes of 24 patients with congenital or developmental lens opacities underwent extracapsular cataract extraction and posterior chamber intraocular lens implantation. Serial measurements were made of axial length, corneal curvature, objective refraction, and visual acuity.

Results-For patients with congenital cataracts (onset $<1$ year age) the mean age at surgery was 24 weeks. Over the mean follow up period of 2.7 years, the mean increase in axial length of $3.41 \mathrm{~mm}$ was not significantly different from the value of an expected mean growth of $3.44 \mathrm{~mm}$ (paired $t$ test, $p=0.97$ ) after correction for gestational age. In the developmental cataract group (onset $>1$ year of age) the mean age at surgery was 6.4 years with a mean follow up of 2.86 years. This group showed a mean growth in axial length of $0.36 \mathrm{~mm}$ that was not significantly different from an expected value of $0.47 \mathrm{~mm}$ (paired $t$ test, $\mathrm{p}=0.63$ ). The mean preoperative keratometry was $47.78 \mathrm{D}$ in the congenital group and $44.35 \mathrm{D}$ in the developmental group. At final follow up the mean keratometry in the congenital group was $46.15 \mathrm{D}$ and in the developmental group it was $43.63 \mathrm{D}$. In eyes followed for at least 2 years, there was an observed myopic shift by 24 months postoperatively of $3.26 \mathrm{D}$ in the congenital cases $(n=10)$ and $0.96 \mathrm{D}$ in the developmental cases $(\mathrm{n}=18)$.
\end{abstract}

Conclusion-The pattern of axial elongation and corneal flattening was similar in the congenital and developmental groups to that observed in normal eyes. No significant retardation or acceleration of axial growth was found in the eyes implanted with IOLs compared with normal eyes. A myopic shift was seen particularly in eyes operated on at 4-8 weeks of age and it is recommended that these eyes are made $6 \mathrm{D}$ hypermetropic initially with the residual refractive error being corrected with spectacles.

(Br F Ophthalmol 1999;83:265-269)

Among the problems which arise regarding the use of intraocular lenses (IOLs) in the paediatric population is the question of the power of the implant that should be used, considering the expected growth of the child's eye. The majority of eye growth takes place in the first 18 months of life after which there is little change. ${ }^{1}$ Animal studies have shown that axial eye growth in the aphakic eye is less than that expected for the phakic eye. ${ }^{23}$ Conversely, animal studies have also shown that axial length increases excessively in eyes in which vision has been obstructed - the phenomenon of visual deprivation myopia. ${ }^{4-6}$ Furthermore, eyes with congenital and developmental cataracts clearly show abnormal ocular development in at least one respect (that is, abnormal crystalline lens formation) and therefore may display different patterns of postnatal growth when compared with normal eyes. Therefore, it is important to determine whether the presence of a cataract obstructing the visual axis in the immature eye and then surgical intervention with cataract removal and IOL implantation will affect the expected pattern of axial eye growth.

This prospective study was undertaken to follow the changes in axial length and corneal curvature in eyes which had extracapsular cataract surgery and posterior chamber IOL implantation for congenital or developmental cataract in childhood.

\section{Methods}

PATIENTS

Thirty five eyes of 24 children aged 4 weeks to 11 years underwent cataract extraction and posterior chamber IOL implantation between 1990 and 1996. Serial measurements of axial length, keratometry, refraction, and visual acuity were performed after surgery.

There were 12 eyes with congenital cataract, defined as cataract diagnosed before 1 year of age. Four patients had bilateral cataracts and four had unilateral cataracts. Developmental cataracts with an onset after 1 year of age were diagnosed in 23 eyes of 16 children, seven bilateral and nine unilateral. In the congenital and developmental groups, eyes with persistent hyperplastic primary vitreous, retinopathy of prematurity, congenital glaucoma, or microphthalmos were excluded. The mean age at surgery was 24 weeks (range 4-94 weeks) in the congenital group and 6.4 years $(1.8-11.8$ years) in the developmental group.

Preoperatively, axial length and corneal curvature were measured with an Alcon Ultrascan Digital B 4000 ultrasound scanner and an Alcon Renaissance automatic keratometer respectively. Postoperatively, these factors were measured at intervals during examination under anaesthesia or outpatient visits, depending on the age of the patient. Comparison between the observed changes in axial length and the expected pattern of postnatal growth 
were achieved with a recently published algorithm ${ }^{7}$ (see appendix) for postnatal eye growth derived from anatomical and ultrasound studies of normal eyes.

SURGICAL TECHNIQUE

Extracapsular cataract removal and posterior chamber IOL implantation were performed. The earlier cases had a limbal incision, can opener capsulotomy, and the Ocutome was used to remove lens material. Later, the incision was changed to a $5 \mathrm{~mm}$ scleral tunnel and the can opener technique was changed to a manual continuous curvilinear capsulorhexis. Manual capsulorhexis was then changed to diathermy capsulorhexis using a Klöti capsulotomy needle (Oertli Instrumente, Switzerland). More recent cases had in addition a posterior capsulorhexis using the diathermy needle to perform capsulorhexis before IOL insertion. No anterior vitrectomy was performed. In all cases Healon GV was used and an anterior chamber maintainer was introduced through clear cornea with an infusion of balanced salt solution. Interrupted 10/0 nylon sutures were used to close the incision. The lens used was a single piece heparin coated 5.5 $\mathrm{mm}$ optic Kabi Pharmacia $809 \mathrm{C}$ or a heparin coated $6.5 \mathrm{~mm}$ optic Kabi Pharmacia 720C. Postoperatively, posterior capsule opacification was managed by performing a YAG laser capsulotomy with a Lasag Microruptor III laser, or in earlier cases a needle capsulotomy was done. Preoperatively, axial length and keratometry measurements were made and lens power was calculated according to the SRK II formula. A correction was then made to this calculated IOL power on the basis of the age of the child at the time of surgery. In the first year of life $6 \mathrm{D}$ was subtracted from the calculated IOL power, from 1 year to 4 years $3 \mathrm{D}$ was subtracted, and from 5 to 12 years $1 \mathrm{D}$ was subtracted.

\section{Results}

OBSERVED AND PREDICTED CHANGES IN AXIAL LENGTH

Congenital cataracts

The overall changes in axial length for patients with congenital cataracts followed for at least 2 years are included in Table 1 . The congenital cataract patients showed the greatest increases in axial length post surgery with a mean increase in axial length over the period of follow up (mean 140 weeks) of $3.41 \mathrm{~mm}$. There was, however, a wide variation in the observed growth rates (range $0.41-8.01 \mathrm{~mm}$ ). Although length of follow up clearly influenced the observed increase in axial length, the main influence on the observed growth rate was the age at the time of surgery. Operations at younger ages were associated with greater degrees of postoperative growth in axial length. Two patients were born prematurely and the rate of eye growth was greatest at birth.

The algorithm provided by Fledelius and Christensen $^{7}$ to determine the expected axial length of the eye by postconceptual age was used to calculate the expected axial lengths for each eye both pre- and postoperatively (see appendix). For each eye the amount of growth expected during the follow up period for that eye could be calculated with this technique. This allows analysis of each eye despite the different lengths of follow up by use of the paired $t$ test on the observed and expected changes in axial length. The mean axial length preoperatively was $18.46 \mathrm{~mm}$ compared with a predicted mean value of $18.55 \mathrm{~mm}$ after correction for postconceptual age (paired $t$ test, $\mathrm{p}=0.84$ ), indicating that these eyes started at the same length as normal eyes of this age. Over the period of follow up for each eye the observed mean increase in axial length of $3.41 \mathrm{~mm}$ was not significantly different from the predicted value of 3.44 (paired $t$ test, $\mathrm{p}=$ 0.97 ) indicating that the overall growth rates in this group of patients was close to that seen in normal eyes. Recalculation of these statistics using only one eye from each patient (always the right in bilateral cases) also demonstrated a close match between observed and predicted growth in axial length with an observed value of $3.61 \mathrm{~mm}$ and a predicted value of 3.29 (paired $t$ test, $\mathrm{p}=0.77$ ).

Figure 1 shows individual axial growth curves for all the congenital cataract cases together with the growth curve predicted from the Fledelius and Christensen algorithm. The broken lines on this plot represent the plus or minus $10 \%$ range for the predicted growth curve. The vast majority of the growth curves lie within this range. This figure also clearly shows that even in eyes with high initial growth rates, the rate of growth slows in line with the expected pattern.

Table 1 Mean axial length measurements preoperatively and postoperatively for congenital cataract eyes followed for at least 2 years

\begin{tabular}{llll}
\hline Patient group & $\begin{array}{l}\text { No of } \\
\text { eyes }\end{array}$ & $\begin{array}{l}\text { Mean axial } \\
\text { length }(\mathrm{mm})\end{array}$ & Range (mm) \\
\hline $\begin{array}{l}\text { Congenital } \\
\text { Preoperative }\end{array}$ & 11 & 18.57 & $16.44-20.00$ \\
12-18 months postop & 11 & 20.66 & $18.97-23.33$ \\
24-30 months postop & 11 & 21.71 & $19.57-24.79$ \\
\hline
\end{tabular}

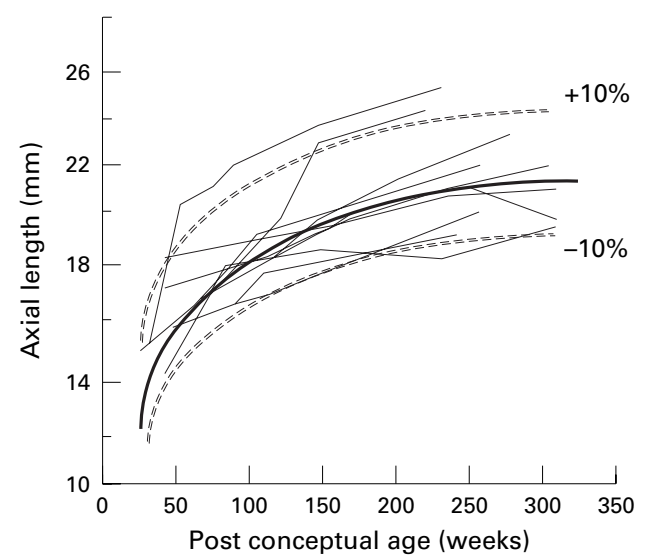

Figure 1 Individual axial growth curves for all congenital cataract eyes over the follow up period. The heavy solid line represents the growth predicted for normal eyes (appendix) with the broken lines showing plus or minus $10 \%$ limits on this normal growth curve. Operated eyes show the same pattern of progressively slowing growth in axial length as normal eyes. 
Developmental cataracts

In keeping with the older age of the patients in the developmental cataract group (mean 6.4 years), the observed rates of axial growth were much smaller than those seen in the congenital

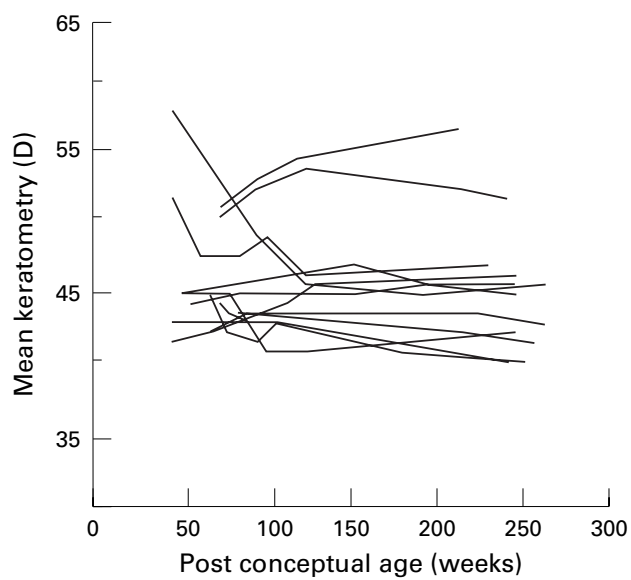

Figure 2 Plot of the mean keratometry values for the congenital cataract group as a function of age. In most cases the keratometry remains stable. Marked reductions in corneal curvature were observed only during the first year of life.

Table 2 Mean keratometry readings preoperatively and at maximum follow up postoperatively

\begin{tabular}{llll}
\hline Patient group & $\begin{array}{l}\text { No of } \\
\text { eyes }\end{array}$ & $\begin{array}{l}\text { Mean K } \\
\text { readings }\end{array}$ & Range \\
\hline $\begin{array}{l}\text { Congenital } \\
\quad \text { Preoperative }\end{array}$ & 12 & 47.78 & $43.55-57.50$ \\
$\quad$ Maximum follow up & 12 & 46.15 & $46.16-56.00$ \\
$\begin{array}{l}\text { Developmental } \\
\quad \text { Preoperative }\end{array}$ & 23 & 44.35 & $42.00-46.75$ \\
$\quad$ Maximum follow up & 23 & 43.63 & $40.625-46.56$ \\
\hline
\end{tabular}

Table 3 Refractive changes (spherical equivalents) following extracapsular cataract extraction and posterior chamber IOL implantation

\begin{tabular}{|c|c|c|c|c|c|c|}
\hline \multirow[b]{2}{*}{ Patient group } & \multirow[b]{2}{*}{ Age at surgery (weeks) } & \multirow[b]{2}{*}{ Patient } & \multicolumn{4}{|c|}{ Months postoperative } \\
\hline & & & 3 & 12 & 24 & 30 \\
\hline \multirow{13}{*}{$\begin{array}{l}\text { Congenital } \\
(n=12)\end{array}$} & 3 & $\mathrm{KD}-\mathrm{L}$ & +1.80 & -2.50 & -4.00 & -9.00 \\
\hline & 4 & $\mathrm{KD}-\mathrm{R}$ & +1.50 & -3.50 & -4.00 & -6.00 \\
\hline & 4 & EMC-L & +6.00 & +7.50 & +6.50 & +2.00 \\
\hline & 4 & EMC-R & +10.00 & +7.50 & +6.50 & +1.75 \\
\hline & 5 & MW-L & +0.50 & plano & & \\
\hline & 7 & DR-R & +4.00 & +4.00 & & \\
\hline & 24 & MD-L & +5.50 & +2.50 & +0.75 & \\
\hline & 24 & $M D-R$ & +6.50 & +2.50 & +0.75 & \\
\hline & 27 & $\mathrm{CN}-\mathrm{R}$ & +5.00 & +0.50 & +1.00 & plano \\
\hline & 45 & COB-R & +1.50 & & -0.375 & \\
\hline & 45 & COB-L & +2.50 & & +1.375 & \\
\hline & 94 & SB-L & +2.25 & +2.25 & +1.50 & \\
\hline & Age at surgery (years) & & & & & \\
\hline \multirow{23}{*}{$\begin{array}{l}\text { Developmental } \\
(\mathrm{n}=23)\end{array}$} & 1.9 & KL-L & +4.75 & +6.50 & +4.50 & \\
\hline & 1.9 & SB-L & +2.25 & +1.50 & +1.0 & \\
\hline & 2 & LL-R & +3.50 & +3.50 & +3.50 & +3.00 \\
\hline & 2 & SB-R & +1.00 & +0.50 & -0.50 & \\
\hline & 2.0 & FF-R & +0.50 & -1.00 & -4.13 & -4.50 \\
\hline & 3.5 & PK-L & - & +2.25 & & \\
\hline & 3.5 & PK-R & - & +1.50 & & \\
\hline & 4.0 & SMC-L & +1.50 & +1.50 & & \\
\hline & 4 & AC-R & -1.50 & -1.50 & -3.0 & \\
\hline & 6 & AE-L & +2.00 & +3.75 & & \\
\hline & 6.1 & AE-L & - & +1.0 & & \\
\hline & 6.5 & DH-R & -2.75 & -2.00 & -2.00 & \\
\hline & 7.2 & GJ-L & -0.88 & -0.88 & & \\
\hline & 7.2 & MS-R & +1.38 & +1.25 & & \\
\hline & 7.7 & GJ-R & -2.50 & -1.00 & -1.00 & \\
\hline & 8.4 & SK-R & +2.00 & +2.00 & & \\
\hline & 8.8 & AB-L & +0.50 & plano & plano & \\
\hline & 9.8 & $A B-R$ & -0.50 & -1.00 & plano & \\
\hline & 11 & $\mathrm{BF}-\mathrm{L}$ & - & - & - & -3.0 \\
\hline & 11 & $\mathrm{BF}-\mathrm{R}$ & +1.00 & +0.25 & -3.25 & -3.0 \\
\hline & 11 & SG-L & -2.38 & -2.00 & -2.25 & -2.25 \\
\hline & 12 & AC-L & -0.50 & -0.25 & -0.75 & \\
\hline & 13 & IT-R & +1.50 & +2.50 & +1.50 & +2.75 \\
\hline
\end{tabular}

group. Over the follow up period for each case (mean 2.86 years) the observed increase in axial length was $0.36 \mathrm{~mm}$.

Comparison of the preoperative axial lengths with the calculated expected values using the same procedure as used for the congenital cataract group indicated no significant difference between eyes with cataracts (mean 21.7 $\mathrm{mm}$ ) and normal eyes (predicted mean for age matched eyes 22.3; paired $t$ test, $\mathrm{p}=0.19$ ). The mean of the expected values of eye growth over the period of follow up for each eye at $0.47 \mathrm{~mm}$ was not significantly different from the observed value of $0.36 \mathrm{~mm}$ (paired $t$ test, $\mathrm{p}=$ 0.63). Recalculation of these statistics using only one eye from each patient (always the right in bilateral cases) also showed a nonsignificant difference with observed growth of $0.27 \mathrm{~mm}$ and a predicted growth of $0.53 \mathrm{~mm}$ (paired $t$ test, $\mathrm{p}=0.32$ ).

OBSERVED CHANGES IN CORNEAL CURVATURE

For the congenital cataract patients there was a degree of progressive corneal flattening in the postoperative period with little change in corneal curvature observed in the developmental cataract group. Figure 2 shows the changes in keratometry over time for all the congenital cataract cases. This figure demonstrates the relative stability of the keratometry values, with marked reductions only being observed only during the first year of life. The mean keratometry in the congenital group preoperatively was $47.78 \mathrm{D}$ and in the developmental group it was $44.35 \mathrm{D}$. At maximum follow up the mean value for the congenital group was $46.15 \mathrm{D}$ and for the developmental group was 43.63. The observed changes in keratometry readings are shown in Table 2.

\section{OBSERVED CHANGES IN REFRACTION}

Table 3 shows the changes in refraction following cataract surgery with IOL implantation in the two groups. Patients are listed chronologically according to the age at time of surgery. In the congenital group, of eyes followed for 2 years $(n=10)$, all but one showed a myopic shift when compared with the refraction at 3 months after surgery, with a mean myopic shift of $3.26 \mathrm{D}$. The greatest shifts are seen in those eye operated on within the first few months of life. In the developmental group postoperative refraction was more stable. Of the 18 eyes with developmental cataracts followed for 2 years the mean myopic shift was $0.96 \mathrm{D}$, with nine eyes showing a myopic shift of at least $0.5 \mathrm{D}$, three eyes showing an hyperopic shift of at least $0.5 \mathrm{D}$ and six eyes remaining within plus or minus 0.50 of first postoperative refraction.

POSTOPERATIVE VISUAL ACUITY

The visual acuity attained following cataract surgery and implantation in the two groups is shown in Table 4, once again arranged chronologically according to their age at the time of surgery. In the developmental group six eyes attained a visual acuity of $6 / 12$ or better and a further six eyes attained $6 / 60$ to $6 / 18$. In the congenital group formal acuity testing was precluded by the age of the patients; however, all 
Table 4 Preoperative and postoperative visual acuity

\begin{tabular}{|c|c|c|c|c|c|c|c|}
\hline \multirow[b]{2}{*}{ Patient group } & \multirow{2}{*}{$\begin{array}{l}\text { Age at } \\
\text { surgery } \\
\text { (weeks) }\end{array}$} & \multirow[b]{2}{*}{ Patient } & \multirow[b]{2}{*}{ Preop } & \multicolumn{4}{|c|}{ Months postoperative } \\
\hline & & & & 3 & 12 & 24 & 30 \\
\hline \multirow{13}{*}{$\begin{array}{l}\text { Congenital } \\
(\mathrm{n}=12)\end{array}$} & 3 & KD-L & - & CSM & CSM & $\mathrm{F}$ and $\mathrm{F}$ & \\
\hline & 4 & KD-R & - & CSM & CSM & $\mathrm{F}$ and $\mathrm{F}$ & \\
\hline & 4 & EMC-L & - & CSM & CSM & CSM & $\mathrm{F}$ and $\mathrm{F}$ \\
\hline & 4 & EMC-R & - & CSM & CSM & CSM & CSM \\
\hline & 5 & MW-L & - & & 6/30FPL & & \\
\hline & 7 & DR-R & - & $\mathrm{CSM}$ & CSM & $\mathrm{F}$ and $\mathrm{F}$ & \\
\hline & 24 & MD-L & - & $\mathrm{F}$ and $\mathrm{F}$ & $\mathrm{F}$ and $\mathrm{F}$ & 6/6Kay & \\
\hline & 24 & MD-R & - & $\mathrm{F}$ and $\mathrm{F}$ & $\mathrm{F}$ and $\mathrm{F}$ & & \\
\hline & 27 & $\mathrm{CN}-\mathrm{R}$ & - & CSM & $\mathrm{CSM}$ & & \\
\hline & 45 & COB-R & - & $\mathrm{F}$ and $\mathrm{F}$ & & $\mathrm{F}$ and $\mathrm{F}$ & \\
\hline & 45 & COB-L & - & $\mathrm{F}$ and $\mathrm{F}$ & & $\mathrm{F}$ and $\mathrm{F}$ & \\
\hline & 94 & SB-L & - & $\mathrm{F}$ and $\mathrm{F}$ & UCUSUM & UCUSUM & \\
\hline & $\begin{array}{l}\text { Age at } \\
\text { surgery } \\
\text { (years) }\end{array}$ & & & & & & \\
\hline \multirow{23}{*}{$\begin{array}{l}\text { Developmental } \\
(\mathrm{n}=23)\end{array}$} & 1.9 & KL-L & UCUSUM & 6/60FPL & 6/60FPL & 3/60FPL & $1 / 60 \mathrm{SG}$ \\
\hline & 1.9 & SB-L & & $\mathrm{F}$ and $\mathrm{F}$ & & $\mathrm{F}$ and $\mathrm{F}$ & \\
\hline & 2 & LL-R & UCUSUM & 6/60FPL & 6/24FPL & 6/18FPL & $3 / 60 \mathrm{SG}$ \\
\hline & 2 & SB-R & & $\mathrm{F}$ and $\mathrm{F}$ & & $\mathrm{F}$ and $\mathrm{F}$ & \\
\hline & 2.0 & FF-R & CUSUM & 6/60FPL & 6/24FPL & 6/24FPL & $6 / 36 \mathrm{SG}$ \\
\hline & 3.5 & PK-R & & & $6 / 12$ & & \\
\hline & 3.5 & PK-L & & & $6 / 36$ & & \\
\hline & 4.0 & SMC-L & CF & $3 / 60 S G$ & $3 / 60 S G$ & $3 / 60$ SG & \\
\hline & 4 & IT-R & $6 / 60$ & $6 / 24 S G$ & $6 / 24 S G$ & $6 / 60$ & \\
\hline & 6 & AE-L & & & & & \\
\hline & 6.1 & AE-R & & & & & \\
\hline & 6.5 & DH-R & $\mathrm{CF}$ & $6 / 60$ & $2 / 60$ & $2 / 60$ & \\
\hline & 7.2 & AC-L & $6 / 18$ & $6 / 12$ & $6 / 12$ & & \\
\hline & 7.2 & MS-R & & $6 / 36$ & $6 / 18$ & & \\
\hline & 7.7 & AC-R & & $6 / 12$ & $6 / 12$ & & \\
\hline & 8.4 & SK-R & & $6 / 18$ & $6 / 18$ & & \\
\hline & 8.8 & AB-L & $6 / 36$ & $6 / 6$ & $6 / 6$ & $6 / 6$ & \\
\hline & 9.8 & AB-R & & $6 / 6$ & $6 / 6$ & $6 / 6$ & \\
\hline & 11 & BF-L & UCUSUM & - & - & - & - \\
\hline & 11 & BF-R & UCUSUM & $\mathrm{F}$ and $\mathrm{F}$ & $\mathrm{F}$ and $\mathrm{F}$ & & \\
\hline & 11 & SG-L & $6 / 18$ & $6 / 6$ & $6 / 12$ & $6 / 24$ & \\
\hline & 12 & GJ-R & $6 / 18$ & $6 / 9$ & $6 / 9$ & $6 / 9$ & \\
\hline & 13 & GJ-L & & $6 / 9$ & $<6 / 60$ & & \\
\hline
\end{tabular}

but one eye showed an acuity of at least central steady and maintained fixation. The best acuity in this group was a bilateral acuity of 6/6 (Kay picture testing).

\section{Discussion}

Axial elongation and changes in corneal curvature are major factors influencing refractive changes in the first few years of life. It is thought that the presence of cataract, surgical removal of the cataract, and the insertion of an IOL may have an influence on axial length and corneal curvature in the growing eye of infancy and childhood. Comparison of our data with published data for normal eyes ${ }^{17-9}$ shows no significant differences in the changes in axial length observed over the follow up period. These results indicate that although significant increases in axial length and an associated myopic shift are seen, particularly in patients operated on within the first year of life, these changes are similar to those expected during the normal growth of the eye. The follow up period is, however, relatively short and it is possible that in later years axial eye growth may deviate from the normal pattern. Nevertheless this study does cover the period during which the eye is undergoing the most rapid phase of axial growth (that is, the first few years of life).

In keeping with previous studies ${ }^{10}{ }^{11}$ there was a general trend towards decreasing keratometric power in the congenital group during the first few months of life, with very little change in the keratometric power within the older developmental cataract group. The ob- served changes in keratometry values and axial length have opposing consequences for the refractive state of the eye. Increasing axial length should lead to a myopic shift and decreasing keratometric values should lead to a hypermetropic shift. Overall, the changes in axial length appeared to outweigh the progressive corneal flattening with age, with both congenital and development cataract patients showing a myopic shift over the follow up period. The shift was most marked in the congenital group reflecting the greater observed increases in axial length, particularly in those eyes operated on within the first 2 months of life. In $50 \%$ of the eyes in this group (6/12) surgery was performed between 4 and 8 weeks of age. In some eyes which started out with a low hypermetropic refraction, the myopic shift leads to a myopic refractive error after 1 year and this was followed by an increase in myopia over the following year.

Half (9/18) of the developmental cataracts followed for two years showed a myopic shift. In most of these cases (7/9) the shift was $1.5 \mathrm{D}$ or less, but two eyes showed large myopic shifts of $4 \mathrm{D}$ or greater. These patients were aged 2 years (FF-R) and 11 years (BF-R ) at the time of surgery. FF-R was unusual in that the axial length increased by $2.06 \mathrm{~mm}(1.41 \mathrm{~mm}$ in the fellow eye) while the corneal curvature remained nearly the same (43.00 D preoperatively and $43.19 \mathrm{D}$ at 2 years postoperatively). $\mathrm{BF}$ was a child with Down's syndrome and bilateral cataracts who had a total retinal detachment in one eye and probably represents a subgroup of patients in which high myopia is common.

The changes in axial length during childhood following implantation of intraocular lenses as noted in this and previous studies of paediatric pseudophakia, create difficulties regarding the choice of the power of the appropriate intraocular lens. ${ }^{12}$ The myopic shifts in pseudophakic eyes are expected to be greater than those observed in normal eyes even if the axial growth follows the normal pattern. This increased myopic shift occurs because in the developing phakic eye progressive flattening of the crystalline lens reduces the refractive consequences of the axial elongation. ${ }^{10}$ Choosing an IOL power appropriate at the time of surgery will result in a marked myopic shift in later years, especially if the operation is performed in the first 6 months of life. Conversely, using powers appropriate to adults will produce high levels of hypermetropia during the first few years of life. In either event the use of spectacle correction is required at some stage in order maximise visual acuity and minimise the risks of amblyopia. Choosing partial undercorrection at the time of surgery will tend to minimise the amount of anisometropia in both the immediate postoperative period and in later life. This is of particular importance in the case of unilateral pseudophakia to avoid problems of spectacle induced aniseikonia.

With regard to the ocular growth patterns of the two oculometric variables affecting the choice of IOL power (keratometry and axial length), it is the change in axial length that 
Table 5 Biometric errors by the age of 10 years that would be expected from normal ocular growth for pseudophakic eyes operated upon at various ages. It has been assumed that the SRK II formula has been used to determine lens power and the lens was chosen to achieve emmetropia in the immediate postoperative period. For operations performed at an early age the SRK II formula includes an adjustment of the $A$ constant due to the short axial length of eyes of this age as shown

\begin{tabular}{llllll}
\hline $\begin{array}{l}\text { Age at surgery } \\
\text { (weeks) }\end{array}$ & $\begin{array}{l}\text { Expected } \\
\text { keratometry } \\
\text { change }(D)\end{array}$ & $\begin{array}{l}\text { Expected axial } \\
\text { length change } \\
(\mathrm{mm})\end{array}$ & $\begin{array}{l}\text { Constant } \\
\text { adjustment for } \\
\text { short eyes }\end{array}$ & $\begin{array}{l}\text { Expected IOL } \\
\text { error (SRK II) } \\
\text { at age 10 }\end{array}$ & $\begin{array}{l}\text { Expected } \\
\text { refractive error } \\
\text { at age 10 }\end{array}$ \\
\hline 4 & -2 & 5.41 & 3 & 14.72 & -11.78 \\
12 & 0 & 4.59 & 3 & 14.47 & -11.57 \\
26 & 0 & 3.71 & 3 & 12.26 & -9.81 \\
52 & 0 & 2.75 & 2 & 8.88 & -7.11 \\
104 (2 years) & 0 & 1.63 & 1 & 5.07 & -4.05 \\
156 (3 years) & 0 & 0.97 & 0 & 2.42 & -1.93 \\
208 (4 years) & 0 & 0.57 & 0 & 1.44 & -1.15 \\
\hline
\end{tabular}

produces the greatest problems in selecting an appropriate power for an IOL. Corneal curvature changes very rapidly during the first few months of life but remains very constant throughout most of childhood and into adulthood..$^{10}{ }^{11}$ For operations even as early as 4 weeks, using peroperative keratometry readings is likely to contribute an underestimate of the appropriate power for later life of only $2 \mathrm{D}$ or so. After 12 weeks very little inaccuracy would be expected to be contributed from keratometry owing to the stabilisation of corneal curvature. ${ }^{11}$ In contrast, the expected axial length changes can be expected to produce very large myopic shifts during childhood. Over the period from 4 weeks to 10 years of age a change in axial length of $5.41 \mathrm{~mm}$ would be expected resulting in a myopic shift in excess of $10 \mathrm{D}$. Table 5 provides a summary of the estimated errors in IOL power and refraction (using the SRK II formula) that would arise by the age of 10 years from normal patterns of eye growth assuming that emmetropia was achieved in the immediate postoperative period. In all cases a greater IOL power would be required at the time of surgery than would be appropriate by the age of 10 years resulting in a myopic shift over time.

IOL implantation in children cannot avoid the need for glasses and individual variations in eye growth will inevitably result in a much greater uncertainty in final refraction than would acceptable in adults. Our policy has been to produce an initial refractive error $6 \mathrm{D}$ of hypermetropia in eyes which are being operated on at 4-8 weeks of age, ${ }^{13}$ the refractive error being corrected with spectacles. The spectacle correction was then gradually decreased over the next 2 years as the myopic shift occurs. In children 1-4 years old we implanted an IOL $3 \mathrm{D}$ less than required for emmetropia since the myopic shift is expected to be less than that for children under a year old. In children aged 5-12 years we aimed for $1 \mathrm{D}$ of hypermetropia.

\section{Conclusions}

This study found that axial growth in eyes operated on for congenital cataracts, with implantation of posterior chamber IOLs, followed closely the pattern observed for normal eyes with the majority of axial elongation taking place in the first 3-6 months life and a gradually reducing rate of growth over the next 2 years. There was a myopic shift in the eyes operated on in the first year of life and this has to be considered in selecting the IOL power. The majority of eyes in the developmental group followed the expected pattern with little axial growth and corneal flattening. Two cases in the developmental group were exceptional and showed a myopic shift. Overall, we have not found a trend towards significant retardation or acceleration of axial growth in the eyes we implanted with IOLs compared with normal eyes.

\section{Appendix}

The second order exponential function given by Fledelius and Christensen for ocular growth in normal eyes based on a data from 126 infants and a number of earlier studies is given below:

$$
\begin{aligned}
f(t) & =f\left(t, K, t_{0}, k_{1}, k_{2}, T_{1}, T_{2}\right) \\
& =K\left[1-k_{1} e^{-\left(\frac{t-t_{0}}{T_{1}}\right)}-k_{2} e^{\left.-\left(\frac{t-t_{0}}{T_{2}}\right)\right]}\right.
\end{aligned}
$$

where $t$ represents the postconceptual age in weeks, $f(t)$ represents the axial length in $\mathrm{mm}$ at age $t$, and with the other variables assigned the following values:

$$
\begin{aligned}
& K=23 \mathrm{~mm} \\
& k_{1}=0.73 \\
& k_{2}=0.27 \\
& T_{1}=12 \text { weeks } \\
& T_{2}=100 \text { weeks, } \\
& t_{0}=10 \text { weeks }
\end{aligned}
$$

The rate of axial growth of the eye ( $\mathrm{mm} /$ week) is given by the expression given below, with other variables as given above:

$$
\frac{d f(t)}{d f}=-K\left[\frac{k_{1}}{T_{1}} e^{-\left(\frac{t-t_{0}}{T_{1}}\right)}+\frac{k_{2}}{T_{2}} k_{2} e^{-\left(\frac{t-t_{0}}{T_{2}}\right)}\right]
$$

1 Gordon RA, Donzis PB. Refractive development of the human eye. Arch Ophthalmol 1985;103:785-9.

2 Wilson JR, Fernandes A, Chandler CV, et al. Abnormal development of the axial length of aphakic monkey eyes. Invest Ophthalmol Vis Sci 1987;28:2096-9.

3 Kugelberg U, Zetterström C, Lundgren B, et al. Eye growth in the newborn aphakic rabbit. $\mathcal{F}$ Cataract Refract Surg 1996;22:337-41.

4 Yinon U. Myopia induction in animals following alteration of the visual input during development: a review. Curr Eye Res 1984;3:677-90.

5 Weisel TN, Raviola E. Myopia and eye enlargement after neonatal lid fusion in monkeys. Nature 1977;266:66-8.

6 Von Noorden GK, Crawford ML. Lid closure and refractive error in macaque monkeys. Nature 1978;272:53-4.

7 Fledelius HC, Christensen AC. Reappraisal of the human growth curve in fetal life, infancy and early childhood. $B r \mathcal{F}$ Ophthalmol 1996;80:918-21.

8 Fledelius HC. Pre-term delivery and growth of the eye. An oculometric study of eye size around term-time. Acta Ophthalmol (Suppl) 1992;204:10-15.

9 Larsen JS. The sagittal growth of the eye. IV. Axial length. Acta Ophthalmol 1971;49:873-86.

10 Gordon RA, Donzis PB. Refractive development of the human eye. Arch Ophthalmol 1985;103:785-9.

11 Inagaki Y. The rapid change of corneal curvature in the neonatal period and infancy. Arch Ophthalmol 1986;104: 1026-7.

12 Awner S, Buckley EG, DeVaro JM, et al. Unilateral pseudophakia in children under 4 years. $\mathcal{F}$ Pediatr Ophthalmol Strabismus 1996;33:230-6.

13 Knight-Nanan DM, O'Keefe M, Bowell R. Outcome and complications of intraocular lenses in children with cataract. $\mathcal{F}$ Cataract Refract Surg 1996;22:730-6. 